David Adam, London

British abattoirs that cull the cattle most at risk from bovine spongiform encephalopathy (BSE) could be spreading the disease to meat sold for human consumption, a report from the Royal Society and the Academy of Medical Sciences has warned.

The report, Transmissible Spongiform Encephalopathies: Statement by the Royal Society and the Academy of Medical Sciences, was issued on 5 June. It suggests that the sheer resilience of prion proteins could be undermining the government's strenuous attempts to keep BSE out of the human food chain.

Eight of Britain's 394 slaughterhouses are regularly used in the government's programme to cull all cattle over the age of 30 months on the basis that these animals pose the greatest BSE risk. The corpses of these older cattle are incinerated - but the same slaughterhouse facilities are also used to prepare meat from younger cattle destined for butchers and supermarkets.

These activities must be carried out on separate days, but the report says that this may not prevent meat intended for human consumption from becoming infected with prion proteins. These are the proteins that are thought to cause BSE in cattle and variant Creutzfeldt-Jakob disease (vCJD) in humans.

Brian Heap, vice-president of the Royal Society, says that results published last year showing that prions may still be active even after they have been heated to $600{ }^{\circ} \mathrm{C}$ (see Proc. Natl Acad. Sci. USA 97, 3418-3421; 2000) throw doubt on the effectiveness of the routine sterilization carried out in slaughterhouses. "Although this observation needs to

\title{
Contracts offer conflict resolution
}

Mark Schrope, Washington

Firm contracts are critical to reducing conflicts in research partnerships between US universities and industry, according to a report prepared by senior representatives of both groups.

The study identifies conflicts of interest that arise when professors and universities have a financial stake in research results as one of the most troublesome problems. Individual researchers should consider stock divestment, full disclosure in all publications, or even resignation from particular projects, it says, whereas universities should develop multiple partnerships to avoid reliance on any one company.

The report, Working Together, Creating Knowledge: The University-Industry Research Collaborative Initiative, was released on 6 June. It is the result of a collaboration between the American Council on Education, an association of 1,800 universities and colleges, and the National Alliance of Business, an industry group.

"We have two different cultures that have to learn to work together," says Nils Hasselmo, co-chair of the panel that produced the report and president of the Association of American Universities, which represents the largest US research universities. The other co-chair was Hank McKinnell, chief executive of Pfizer, the New York-based pharmaceutical company.

McKinnell says that one of the most important recommendations is that collaborations should have contracts that cover every aspect from the outset. Many

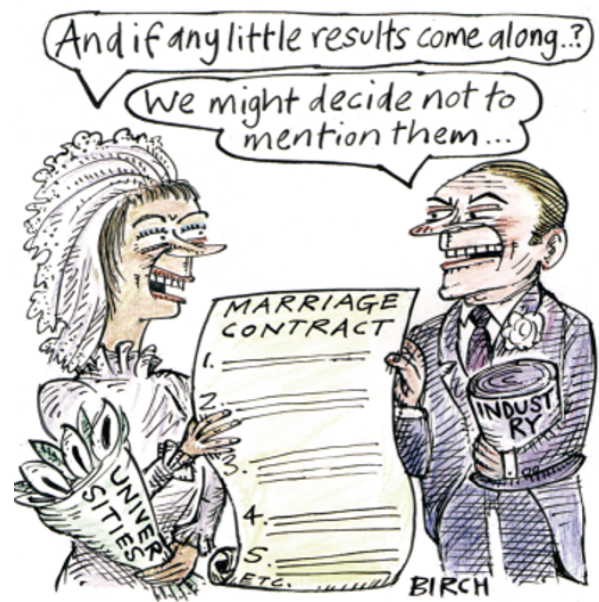

universities and researchers start working together with significant portions of these agreements incomplete, he says.

The report also advises companies that they should pay the full overhead rate set by the federal government for each university, over and above the direct costs of research. Traditionally, many companies have negotiated lower rates.

But Sanford Chodosh, president of Public Responsibility in Medicine and Research, an ethics organization based in Boston, says that the report does not go far enough in addressing the problem of conflicts of interest in clinical research. He says that the report failed to address, for example, the ways in which companies influence the choice of research results that are made public. "A lot of the stuff that gets done never gets published," he says. be confirmed, we need to establish conclusively that work surfaces and equipment in abattoirs are not contaminated after the usual cleaning and sterilization procedures," Heap says.

Contamination of meat with prions from infected brain tissue by butchers' equipment was recently blamed for a cluster of cases of vCJD in the Leicestershire village of Queniborough (see Nature 410, 502; 2001).

The report also recommends that new methods be considered for disposing of the vast mountains of potentially contaminated animal matter being stored in the United Kingdom. Some 430,000 tonnes of meat and bone-meal and 200,000 tonnes of tallow are held in storage, awaiting disposal. "We believe the authorities should consider eliminating this waste with meat-eating bacteria or through incineration without air at $850^{\circ} \mathrm{C}$," Heap says. He also points out that storing the waste is expensive and potentially hazardous.

The new report follows close on the heels of a modelling survey, commissioned by the Department of Health to address concerns about the transmission of vCJD by surgical instruments. This report concluded that surgical transmission could increase the size of the epidemic by up to $10 \%$.

In response to such fears, the govern-

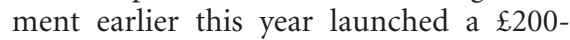
million (US\$280-million) programme to improve sterilization procedures, and to use disposable instruments for operations that carry a particularly high risk of passing on the infection. But this is unlikely to have eliminated the risk entirely.

The Royal Society/Academy of Medical Sciences report also highlights the need to develop sensitive and cheap tests that would allow large numbers of live animals to be tested for BSE infection before they show symptoms of disease. Current tests have only been validated on brain tissue from animals that are known to have BSE. However, researchers are now working to develop methods that might detect prions in tissues such as blood before the appearance of symptoms (see page 810 ).

Another aspect of the problem that is highlighted by the new report concerns the uncertain job status of many BSE researchers. The report warns that shortterm contracts for postdoctoral researchers are hampering research because they make it difficult for young scientists to commit themselves to the field. Research agencies "should consider creating some prestigious longer-term (five- to ten-year) fellowships and longer-term grants", it says. 